INTERNATIONAL DESIGN CONFERENCE - DESIGN 2018

https://doi.org/10.21278/idc.2018.0440

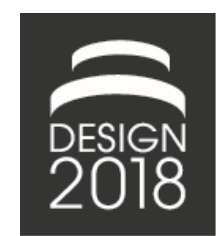

\title{
DECISION SUPPORT TOOL TO DERIVE SUSTAINABLE PRODUCT CONFIGURATIONS AS A BASIS FOR CONCEPTUAL DESIGN
}

\author{
T. Buchert and R. Stark
}

\begin{abstract}
Developing sustainable products requires a thorough understanding of the product and its environmental, economic and social impact. In particular decision-making in conceptual design has a large influence on sustainability performance of the final product but still remains widely unsupported. Hence, an Engineering Decision Support System (EDSS) and a corresponding method is proposed which assists system engineers in evaluating and comparing various product concepts in early design phases. In this paper the EDSS concept is elaborated and demonstrated on the example of a pedelec drive system.
\end{abstract}

Keywords: sustainable design, product lifecycle management (PLM), decision making

\section{Challenges of decision making in conceptual design to create sustainable products}

In the course of the last years the topic of sustainability and associated environmental, societal or economic implications became one of the major topics in public debate. Intergovernmental efforts, such as the UN Sustainable Development Goals (United Nations General Assembly, 2015) aim to make the most crucial challenges visible and to foster action in the upcoming decades. One of the major goals in this context is the search of a pathway towards responsible consumption and industrial production. A necessary condition to achieve this target is based on safe and affordable products with a high value for the customer and a minimal impact on the ecosphere in terms of emissions and resource consumption. Nevertheless, despite ground-breaking works like The Limits to Growth by Meadows et al. (1972) current habits for production and resource consumption still exceed the planetary boundaries for resource consumption and environmental impacts (Erb et al., 2012). In 2010 the amount of $15.7 \mathrm{Gt} \mathrm{CO} 2$ eq., i.e. $32 \%$ of global greenhouse gas emissions, can be attributed to industrial production (IPCC, 2014). Moreover, $28 \%$ of particulate matter (PM2.5 and PM10) were emitted by industrial processes (European Environment Agency, 2014). A significant share of this burden is induced through production of longlasting industrial or consumer goods (in particular machinery, vehicles and electronic products). In addition to process-related emissions of production these goods most often also cause harmful effects in their usage (e.g. combustion of fossil fuels in traffic) or in the end of life phase (e.g. by handling toxic materials).

To tackle these challenges various policy instruments, business models and technologies were introduced, most often focusing the production or use phase of products. To complement these measures the product design process is a well-recognized lever to achieve improvements before the product is even manufactured. In particular the conceptual design phase determines product performance in all 
sustainability dimensions and phases of the product life cycle to a large degree as major decisions on product architectures, solution principles as well as technology options are made in this phase.

Due to this large potential, many researchers contributed to the fields of Environmental Product Development or Ecodesign which later evolved to the more holistic view of Sustainable Product Development (SPD). One of the most eminent streams within SPD research is the development of new methodological support for design engineers to enable better decision-making (see for example Buchert et al., 2017). Baumann et al. (2002) already presented in 2002 a scheme to classify available approaches in Checklists and Guidelines, Analytical Tools (focused on quantitative assessment, e.g. Life Cycle Assessment), Rating and Ranking Tools (simple qualitative tools for comparison e.g. LiDS-Wheel, Brezet et al., 1997), Organizing Tools (interactive group based tools, e.g. and Software/Expert Systems (see below). Furthermore, various combinations of tools from these categories are available (see Buchert et al., 2017). One recent example is the integrated eco-design decision-making methodology (IEDM), a combination of an extended QFD approach with LCA (Romli et al., 2015).

Another possible perspective on these approaches is to differentiate prospective and retrospective methods (Poudelet et al., 2012). Retrospective methods are focused on giving a precise estimate of a product's sustainability behaviour, e.g. in terms of environmental impact or life cycle cost. Due to their high demand of information, these tools are rather used towards the end of the design process or when the product is already manufactured. Prospective methods rather aim to address the beginning of the design process, where the design space is still open for achieving pivotal sustainability improvements. Most common tools of this category are checklists and guidelines consisting of "heuristics" or "rules of thumb" to identify potential for sustainability improvements. While many guidelines for Ecodesign exist, only few approaches for considering sustainability are available (e.g. Crul and Diehl, 2006). One risk of using generic advices, such as "use lightweight design to reduce fuel consumption and the amount of produced material for saving energy" is to neglect negative side effects which may occur when following a design principle in a specific application case. In some cases positive effects can be overcompensated when different sustainability indicators and phases of the product life cycle are considered (e.g. higher emissions for production of lighter materials to realize a lightweight design). Another well-known prospective tool for Ecodesign is the Simplified Life Cycle Assessment (SLCA) approach. It uses predefined databases for materials, production processes and means for transport to calculate selected (mostly environmental) indicators on component or product level.

What is usually not considered by these support tools is product-functionality. According to well-known models of the product creation process, such as the VDI 2221 or VDI 2206, a product design starts with given requirements and a corresponding functional description. From that point, different solution principles are researched and compared against each other (e.g. through morphological analysis, see for example Pahl et al., 2007). The choice of functions and corresponding solution principles can be seen as most important decisions in the context of product sustainability as the overall solution space is strongly diminished already with these tasks. By selecting a solution concept a limited range of possible functional carriers with their most common materials and manufacturing processes remains as an option. Furthermore, overall efficiency and effectivity in product usage, e.g. in terms of cost, environmental impact or customer satisfaction as well as possible ways for end of life processing are determined at least in certain ranges (e.g. by selecting a less efficient way of transmitting energy between two rotating elements). Hence, further optimization after this point, e.g. through material savings due to a lightweight design approach, may only lead to a local optimum instead of the best solution from a global viewpoint. Despite the significance of functionality for a product's sustainability, only few approaches focus on this topic. In the specific perspective of Life Cycle Assessment the term Functional Unit (see ISO14040) is used to define a given set of functions as a basis of comparison in terms of environmental performance, e.g. to compare the impact of travelling $100 \mathrm{~km}$ by car or by train. In this case the distance defines the baseline for a functional unit. A functional unit for comparing products is usually complex as a wide variety of functions is considered. Functional models (e.g. by Pahl et al., 2007) can be considered as a reference for a functional unit in product design. Hence, the concept of functional unit can also be used in product design for strategic comparison of technologies or validation of redesign projects if addressed functionality can be considered as comparable (what is not always realistic). 
In addition, approaches to select functions regarding their sustainability impact were developed. Oberender and Birkhofer (2004) presented the Eco-Value Analysis which relates functions to possible impacts of associated components and gives hints which function to realize and which not. The Function Impact Matrix presented by Devanathan et al. (2010) uses a comparable mechanism and provides an overview how much each function contributes to an overall indicator, such as the carbon footprint. Both approaches follow the idea of retrospective analysis of one existing product and its components with LCA. On that basis appropriate functionality for redesign purposes is defined.

While these approaches focus on improving one single product, configurators can be seen as another option to better integrate sustainability into product designs. Commercial configurators, such as the Siemens Drive Technology Selection Tool already allow finding product configurations compliant with targets for energy consumption and Total Cost of Ownership. However, these tools are focused on increasing transparency of external product variety for the customer without taking into account internal variety including design and production constraints (e.g. material energy consumption).

Arnold et al. (2008) went one step further by developing an interactive morphological matrix tool for automated concept generation (MEMIC) specifically dedicated to design. MEMIC allows generating concepts on the basis of product functions and a design repository of existing classified components (i.e. a configuration tool for supporting conceptual design). Bohm et al. (2010) used this tool to evaluate and compare generated concepts with a simplified LCA and corresponding environmental indicators. While the general approach seems promising, evaluation of every alternative with simplified LCA requires a lot of effort. Hence, only the most promising variants can be compared with LCA leading to additional iterations if these variants are not compliant with environmental goals. Further shortcomings of this approach are an oversimplified consideration of the product life cycle (e.g. estimation of energy consumption in usage for every concept), as well as limited flexibility for considering a mix of new components and carry-over parts (concepts can only be build based on the components in the utilized repository).

While a loose coupling of MEMIC and LCA can be seen as a first important step for early phase prospective decision support, a comprehensive framework for design configurators specifically dedicated for decision support is still missing. Hence, this paper aims at answering two questions:

- What are the characteristics of a configuration tool for decision support to identify sustainable design concepts? How can such a tool be applied in a design project?

- What type of resources in terms of additional effort, knowledge and information is necessary to realize such an approach?

The formulated research questions are part of a larger project focusing on the development of an engineering decision support system (EDSS) for Sustainable Product Development. The research gaps addressed by the EDSS were derived in a large scale literature study (Buchert et al., 2017), interviews and workshops with industry (Buchert and Stark, 2018) as well as experiences gathered in a real development project (Stark et al., 2017). In the following chapter the general idea of an EDSS for Sustainable Product Development is introduced. The specific use case of configuration assistance is presented in Chapter 3. In this chapter respective tool functions are introduced and illustrated on the example of pedelec drive system development. In Chapter 4 this approach is reflected and respective benefits and obstacles are explained. Furthermore, the work is concluded in Chapter 5.

\section{An engineering decision support system (EDSS) for sustainable product development}

To consider consequences of decisions in product design on sustainability requires taking into account various design parameters which enhance conventional functional requirements and the "golden triangle" of quality, time and cost. Figure 1 gives an overview of criteria-categories which can be used to decompose the fuzzy term sustainability into different sub-criteria (based on Shuaib et al., 2014). Considering this enhanced set of criteria in one context can already be seen as a complex task. The criteria need to be prioritized and various trade-offs are to be solved. This task becomes even more complex when all phases of the product life cycle are considered at the same time. Life Cycle thinking 
is a necessary condition for sustainability as it is the key to identify improvement potential by avoiding "problem shifting" (e.g. shifting emissions from usage to production) at the same time.

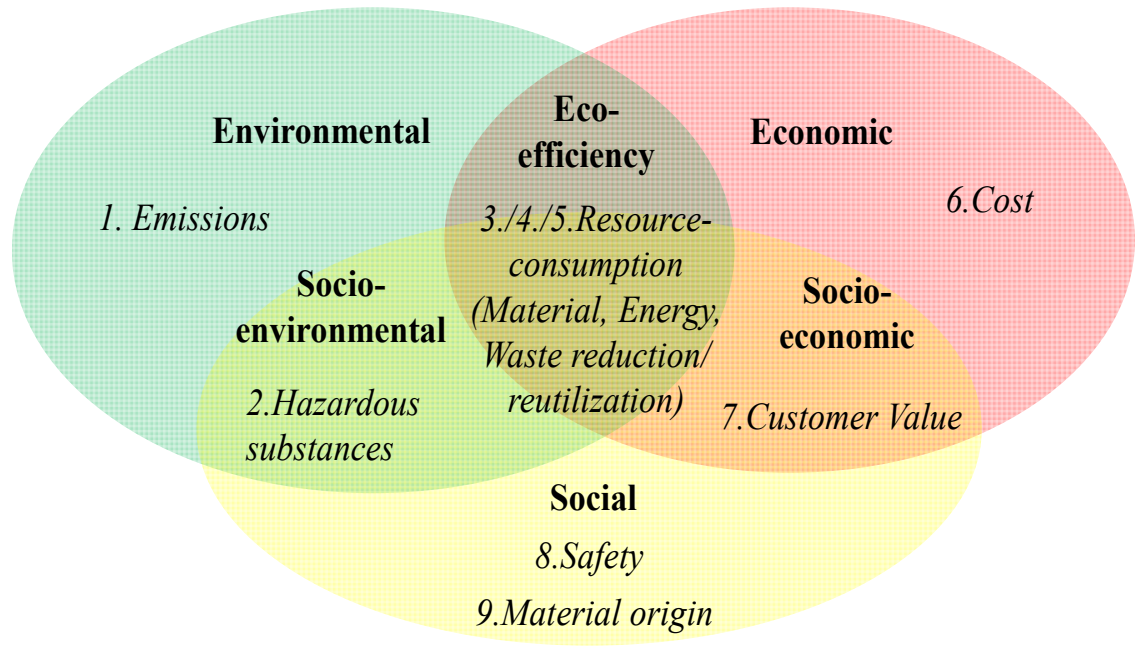

Figure 1. Relevant sustainability factors (based on Shuaib et al., 2014)

To cope with this enhanced complexity an EDSS is proposed which supplies engineers with required knowledge and information as well as algorithmic support to put respective information into perspective and filter most relevant information for decision making. Figure 2 gives a conceptual overview of the building blocks of such a system. One underlying principle highlighted in this figure is a differentiation into two different views on the EDSS, a design engineer and an expert view. The term "expert" represents relevant stakeholders of a company located in different company departments, which define and monitor specific requirements on the product in the context of sustainability factors introduced in Figure 1. Hence, these actors supply models and information to better assess respective performance indicators (e.g. a mathematical model for calculating maintenance cost can be supplied by a cost engineer). Another exemplary model-type represents material and energy flows occurring in the product life cycle (LCA models). These process-based models can be supplied by environmental experts for example.

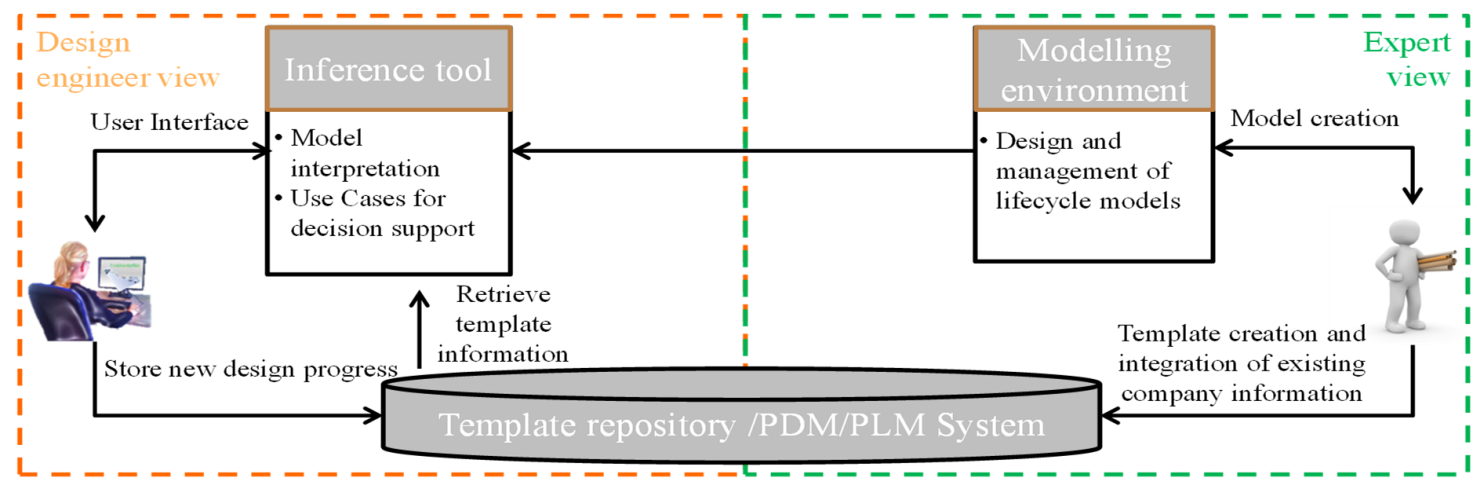

Figure 2. Elements of an EDSS for sustainable product development

Since the application of models for decision support requires much information it is also necessary to orchestrate available information in the company for that purpose. As proposed in guideline 5610 part 2 by the Federal Association of German Engineers (Verein Deutscher Ingenieure, 2017) there will be a call for a new job role in addition to experts from specific technical fields to fulfil this goal (knowledge engineer). Knowledge engineers are responsible for integrate the different models into the EDSS (Modelling Environment). Furthermore, they guarantee availability of information for calculating required indicators which can be directly attached to models of parts, assemblies and products stored in a PDM/PLM system (e.g. cost, emissions etc.). If this information is available for different products 
and/or product variants it can be utilized for decision support to develop subsequent product generations (knowledge templates). Knowledge templates can be used to represent attributes of the same component which is used in another product (carry over part) or for similar components (e.g. different types of screws with similar dimensions). To make use of templates a reasoning tool is necessary to bring different templates in one context (e.g. generation of solution concepts or direct comparison of templates) and to apply the models defined by experts.

\section{Assistance for configuration of sustainable product concepts}

The last chapter gave a brief introduction of the overall EDSS concept. In the following paragraphs the specific EDSS use case of finding suitable product configurations based on technical requirements and sustainability targets will be introduced in detail.

As a starting point the basic information model behind the configurator was defined (see Figure 3 ). The model is based on the well-known approach of Pahl and Beitz for conceptual design which separates functions and alternative solution principles to realize functions. Solution principles are characterized by a combination of components and assemblies (functional carriers) leading to a desired physical effect (e.g. a mechanical transmission of energy achieved through friction and fundamental laws of force and movement). Functional carriers are usually available in variants to reflect different interface types, dimensions or quality levels. Both functional carriers as well as solution principles can be described by attributes reflecting granularity of the system (e.g. energy consumption for producing one motor part vs. overall efficiency of a drive system). To determine attributes of solution principles, functional carrier attributes need to be considered in conjunction. In some cases calculation of these system parameters is simple (e.g. sum of component weight for calculating system weight). In other cases analysis becomes more difficult as it depends on dynamic parameters, such as system usage (e.g., energy demand).

Function

Solution Principle

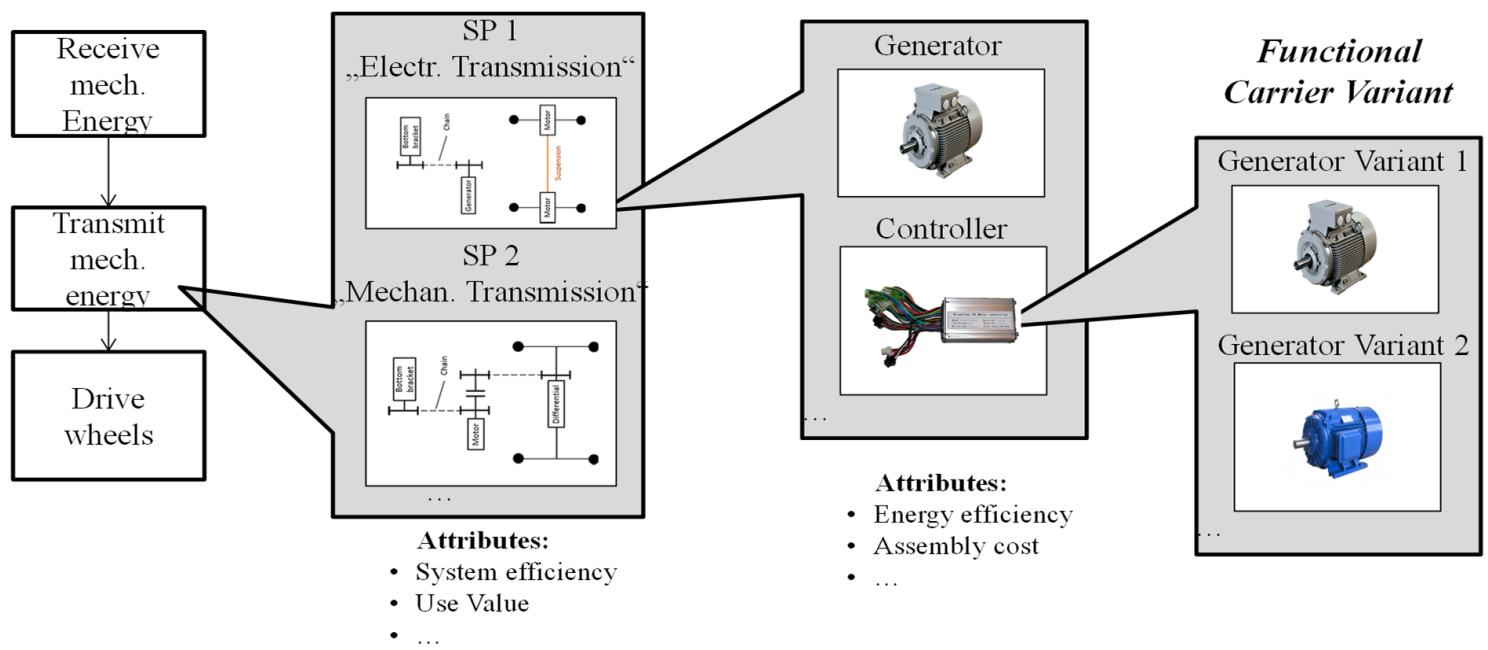

Figure 3. Basic information model for product configuration

The described information model provides the basis for building up a repository of existing productrelated information in a company. If all existing products are classified regarding this scheme, the resulting knowledge base can be used to compare various possible product configurations regarding targets. For considering sustainability, the factors introduced in Figure 1 need to be considered in conjunction as far as possible. Furthermore, they have to be broken down to the form of quantifiable Key Performance Indicators. These KPI can be based on existing KPI schemes which are already followed in the design process (e.g. cost or quality targets). To limit effort for data collection and data processing, only the most relevant attributes should be taken into account based on product-specific sustainability impact (sustainability hotspots).

Figure 4 shows a first proof of concept for a toolset which is based on the information model introduced above to realize the proposed EDSS-configuration function. The core configuration and decision logic 
was implemented in Matlab. Furthermore, QT Visual Studio is used for simplifying formalization of product/product family information and for realizing interactive plots of the results. In addition, Excel is used to store product-related data. In later steps, Excel should be substituted with a relational database to cope with larger amounts of data.

\begin{tabular}{|c|c|}
\hline \multicolumn{2}{|c|}{ QT Visual Studio } \\
\hline $\begin{array}{l}\text { Graphical editor for simplifying formalization } \\
\text { of product/product family information }\end{array}$ & $\begin{array}{l}\text { Interactive plot for identifying viable config- } \\
\text { urations and respective KPI-performance }\end{array}$ \\
\hline Excel & \\
\hline $\begin{array}{l}\text { Storage of product/product familiy } \\
\text { information and KPI values }\end{array}$ & \\
\hline \multicolumn{2}{|c|}{ Matlab } \\
\hline $\begin{array}{l}\text { Configuration and filtering of solution concep } \\
\text { requir }\end{array}$ & $\begin{array}{l}\text { rgarding sustainability targets and technical } \\
\text { ments }\end{array}$ \\
\hline
\end{tabular}

Figure 4. Composition of developed tool functions

Figure 5 shows the different steps of the corresponding method to the introduced toolset. Furthermore, necessary information for applying the method is given. In this context, conceptual links to already existing engineering tools and repositories are drawn. In particular PDM/PLM systems can be a crucial source of information concerning product attributes (e.g. weight, cost) as well as product structure and associated BOM. In addition, PDM/PLM can be a source for information on product variability (e.g. via $150 \%$ product structure or configuration rules). While functional carriers and respective variants can be derived from PDM/PLM, principles and functions are typically not available. In this context, graphical modellers can be a complementary source of information.

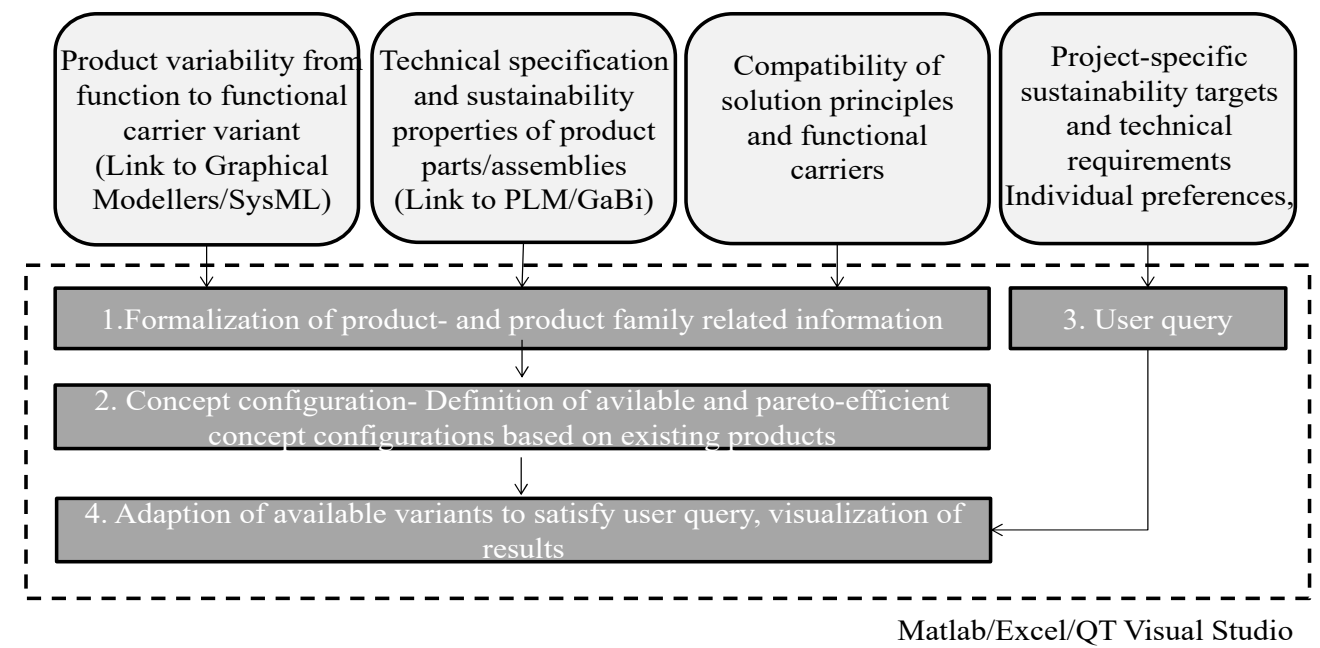

Figure 5. Workflow for utilizing the EDSS configuration tool

While QT is used in the first tool-prototype, existing modelling notations (e.g. SysML) and corresponding modelling tools (e.g. PTC Integrity Modeller) also capture information on product functions and subsystems by a graphical representation to increase overview on system dependencies. Another option is the METUS modelling tool which is specifically focused on the evaluation of product architecture definition as support of complexity management and modularization. To gather environmental impact data the LCA tool GaBi can be coupled to PDM and/or the developed configuration tool. Until now, interfaces to the configuration tool are only considered conceptually. The following chapters describe respective steps introduced in Figure 5. The development of a concept for a pedelec drive system is used as a continuous example for further illustration. 


\subsection{Formalization of product- and product family related information}

As a first step available product information needs to be adapted to the information model described above. Figure 6 shows the sequence of action necessary to derive a suitable formalization. The process starts with a definition of product or product family functions (Func). Afterwards, solution principles (SP) and functional carriers (FC) with respective carrier variants (CV) are added in the form of a decision tree. These two steps are currently realized with QT Visual Studio.

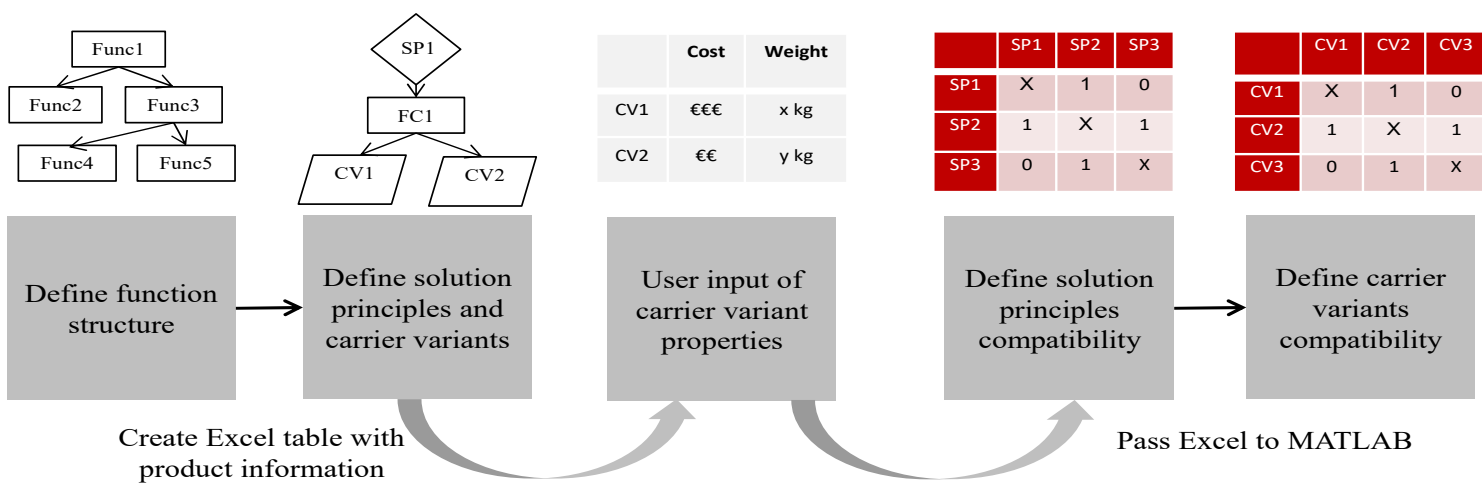

Figure 6. Formalization of product- and product family related information (Step 1, Figure 4)

The developed structure can be exported to Excel. Here, the different attributes can be added for every functional carrier. The created Excel lists can be imported into Matlab where the configurations are calculated. As a last step of data-formalization, a matrix for declaring incompatible SPs and CVs needs to be filled in Matlab.

Table 1 shows how different configuration options for a pedelec drive concept can be represented by following this approach.

Table 1. Example pedelec drive system

\begin{tabular}{|c|c|c|c|}
\hline Function & Solution Principles & Functional Carriers & Functional Carrier Variants \\
\hline \multirow{3}{*}{$\begin{array}{l}\text { Transmit mechanical energy } \\
\text { from pedal to wheel }\end{array}$} & \multirow{2}{*}{ Electrical transmission } & Generator & $\mathrm{Tx} 72$ \\
\hline & & Cable & Cable \\
\hline & Mechanical transmission & Chain & Chain \\
\hline \multirow{8}{*}{ Electrical support for driving } & \multirow{2}{*}{2 motors, rear } & \multirow{2}{*}{ Electric Motor } & DMG \\
\hline & & & Ansmann \\
\hline & \multirow{2}{*}{2 motors, front and middle } & \multirow{2}{*}{ Electric Motor } & DMG \\
\hline & & & Ansmann \\
\hline & \multirow{2}{*}{ One motor front } & \multirow{2}{*}{ Electric Motor } & DMG \\
\hline & & & Ansmann \\
\hline & \multirow{2}{*}{ One motor middle } & \multirow{2}{*}{ Electric Motor } & DMG \\
\hline & & & Ansmann \\
\hline \multirow{2}{*}{$\begin{array}{l}\text { Switch to „Charging while } \\
\text { standing }\end{array}$} & Derailleur & Derailleur & Shimano \\
\hline & Coupling & Coupling & Xt35 \\
\hline \multirow{2}{*}{$\begin{array}{l}\text { Realize „Charging while } \\
\text { standing“" }\end{array}$} & Generator & Generator & Tx72 \\
\hline & Motor as generator & Electric Motor & \begin{tabular}{|l|} 
Ansmann \\
DMG \\
\end{tabular} \\
\hline \multirow{3}{*}{ Enable different wheel-speed } & Differential & Differential & Typ Hase \\
\hline & \multirow{2}{*}{ Electronic Differential } & Electric Motor & Ansmann \\
\hline & & Controller & Ansmann \\
\hline
\end{tabular}

The table shows basic functions to achieve, when realizing a drive system, such as transmission from mechanical energy from pedal to wheel as well as electrical support for driving. Furthermore, the drive system allows charging the battery through pedalling while the pedelec is not moving. In addition, different wheel-speeds shall be possible for increasing stability in curves. The table also shows solution principles 
(e.g. motor configurations, differential options), functional carriers (e.g. Generator) and specific variants (e.g. Ansmann Controller). To model these dependencies in the configuration tool QT Visual Studio is used. For representing sustainability targets for the drive concept, four indicators were chosen: $\mathrm{CO} 2$ emissions (production and operation, environmental perspective) and cost (production and operation, economic perspective). Weight was also included as an exemplary technical requirement (it could also be argued that weight is representing sustainability, since weight is simplifying operation of the pedelec by its user). Then, respective values for weight, $\mathrm{CO} 2$ emissions (production) and cost (production) were directly assigned to functional carrier variants. $\mathrm{CO} 2$ emissions and cost in operation are considered via a model (see below). Afterwards conflicting solution principles and functional carriers were highlighted in the tool.

\subsection{Concept configuration}

The second phase of configurator design and application is directed towards building concepts out of the defined structure of functions, solution principles, functional carriers and carrier variants. Figure 7 shows necessary steps to define the configurations. At first all technically viable configurations are built automatically based on information given in the compatibility matrices. Afterwards, system attributes are calculated for each targeted attribute. To achieve this aim product specific models represented by mathematical formula are necessary (e.g. to determine energy consumption of a given configuration in its usage phase). If all configurations are assigned with their respective performance in considered attributes, inefficient variants can be eliminated. Hence, an algorithm for pareto efficiency is applied automatically which eliminates inefficient solutions. Thus, only concepts on the pareto frontier of considered dimensions are taken into account in further steps. To allow a larger spectrum of concepts, the user can define an interval of tolerance for every factor.

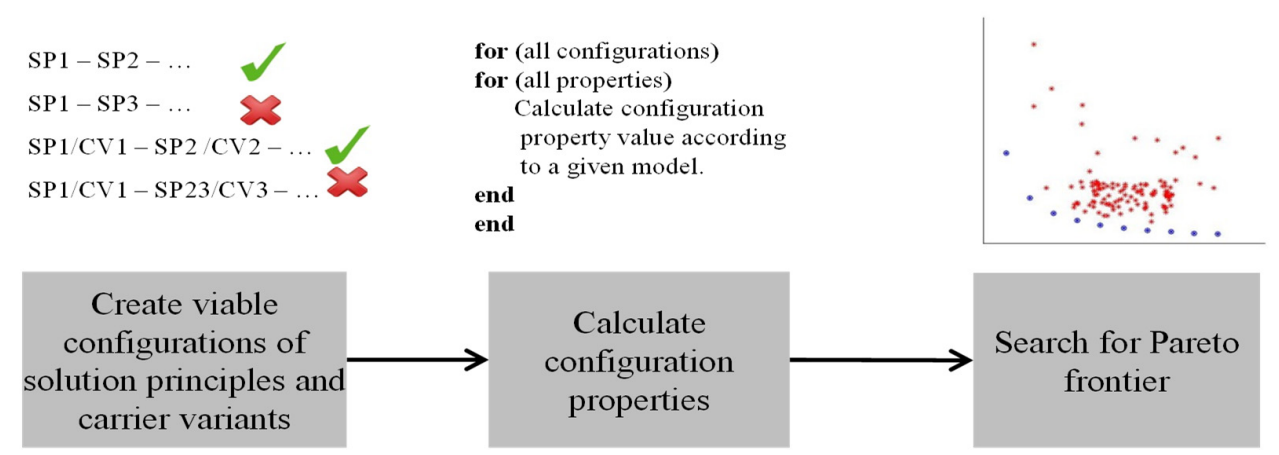

Figure 7. Concept configuration (Step 2, Figure 4)

For the pedelec drive concept various viable variants were found. The configuration properties weight, $\mathrm{CO} 2$ emissions and cost in production can be easily calculated through summation of respective carriervariant values. For calculation of cost and $\mathrm{CO} 2$ emissions in usage a simplified model was developed. To calculate energy demand, the theoretical power necessary to move the pedelec (Ptheo) is estimated and then, in a subsequent step merged with a usage-profile of a reference user:

$$
\text { Ptheo. }(\mathrm{t})=\text { FAir Resist. }(\mathrm{t})+\text { FRolling Resistance }(\mathrm{t})+\text { FGrade Resistance }(\mathrm{t})+\text { FInertia }(\mathrm{t})) * \text { vUser }(\mathrm{t})
$$

Consideration of components' efficacies in the powertrain of the concept variants allows calculating the net power needed from the battery. In combination with extrinsic variables (e.g. cost per unit energy), the contribution of the actual use of the pedelec towards the target parameters (e.g. cost) is computed. This core model is then extended by a component's maintenance and repair predication model, which ultimately allows the integration over the defined use-phase and determination of the overall contribution of the use-phase to the target indicators. A more detailed description of models for calculation performance attributes will be delivered in future publications due to the limited scope of this article.

\subsection{User query and adaption of available variants}

After the knowledge base is defined and available configurations are built it is now shown how the actual user (system engineer) interacts with the tool (see Figure 8). 

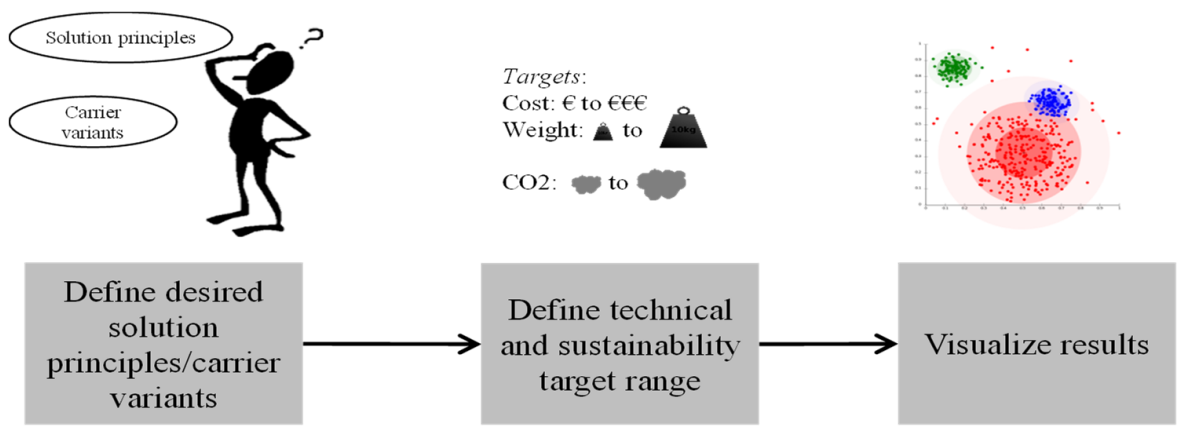

Figure 8. User query and adaption of available variants to user query (Steps 3 and 4, Figure 4)

Assuming a new design project, the system engineer wants to identify viable solution concepts to fulfil a set of given sustainability targets. The tool user-interface allows to browse through available functions, solution principles, functional carriers and carrier variants and to select whether to include these entities in a new product. While it is possible to define carrier variants which shall be included in every configuration it is also feasible to define a function without specifying which solution principle to follow. In this case different solution principles can be compared. This pre-selection of configuration elements is used as a filter to decrease the amount of all available concepts generated before (see previous chapter).

As new products also include new components, which do not exist in the conceptual design phase, a placeholder can be defined. Placeholders can be allocated with an estimated sustainability impact (such as $\mathrm{CO} 2$ emissions or cost). With this function it becomes possible to allocate a given budget of product sustainability impact between existing and new components to define appropriate targets for design of these new modules.

If the desired functions, solution principles and functional carriers are selected, technical requirements and sustainability targets can be assigned to the overall system and system elements as an additional filtering option for available product concepts. Targets can be defined with a fixed value (e.g. $\mathrm{x} \mathrm{kg} \mathrm{CO} 2$ ), in a range between two values or with operators $(<,>$ etc.). Finally, the result of the query is visualized by a plot generated in QT Visual Studio. The plot can show the results in various dimensions. Furthermore, it is possible to compare different search queries (e.g. to evaluate the effect of a product function on sustainability).

Figure 9 shows the GUI of the developed configuration tool including data for drive concept design. In this query three different filtering scenarios (combinations of defined solution concepts, functional carriers, sustainability targets und technical requirements) are selected.

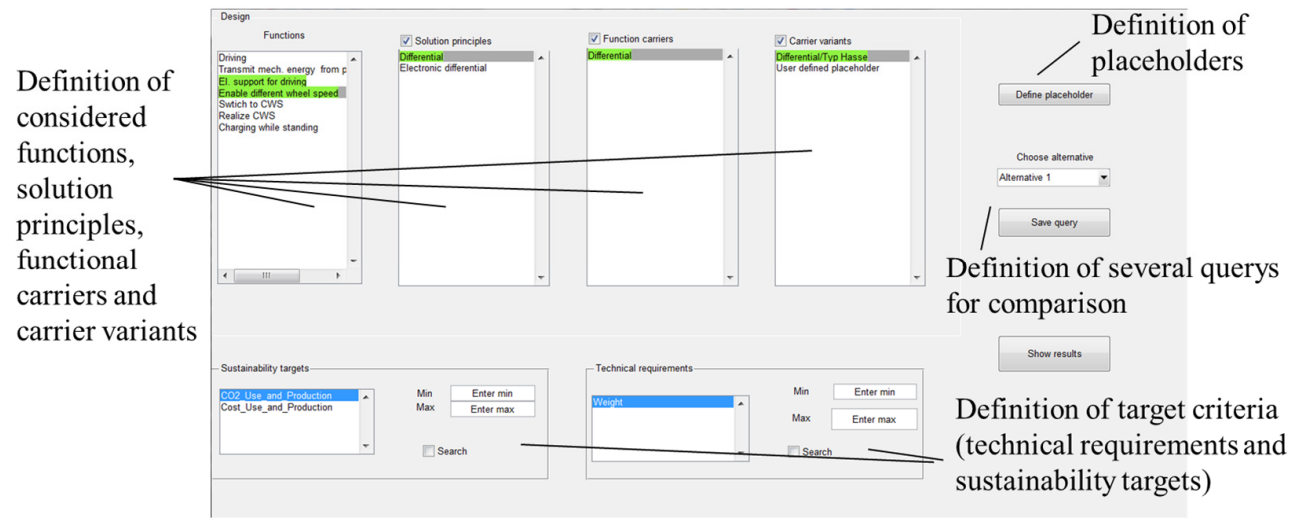

Figure 9. GUI for user query

Figure 10 shows the visualization of results from this query. The different shape of the green elements reflects the three defined filtering scenarios. On the right side of the screen information on a selected configuration is given. In the selected configuration 4 existing components are combined. The Differential shall be a new development and is therefore defined as a placeholder. 


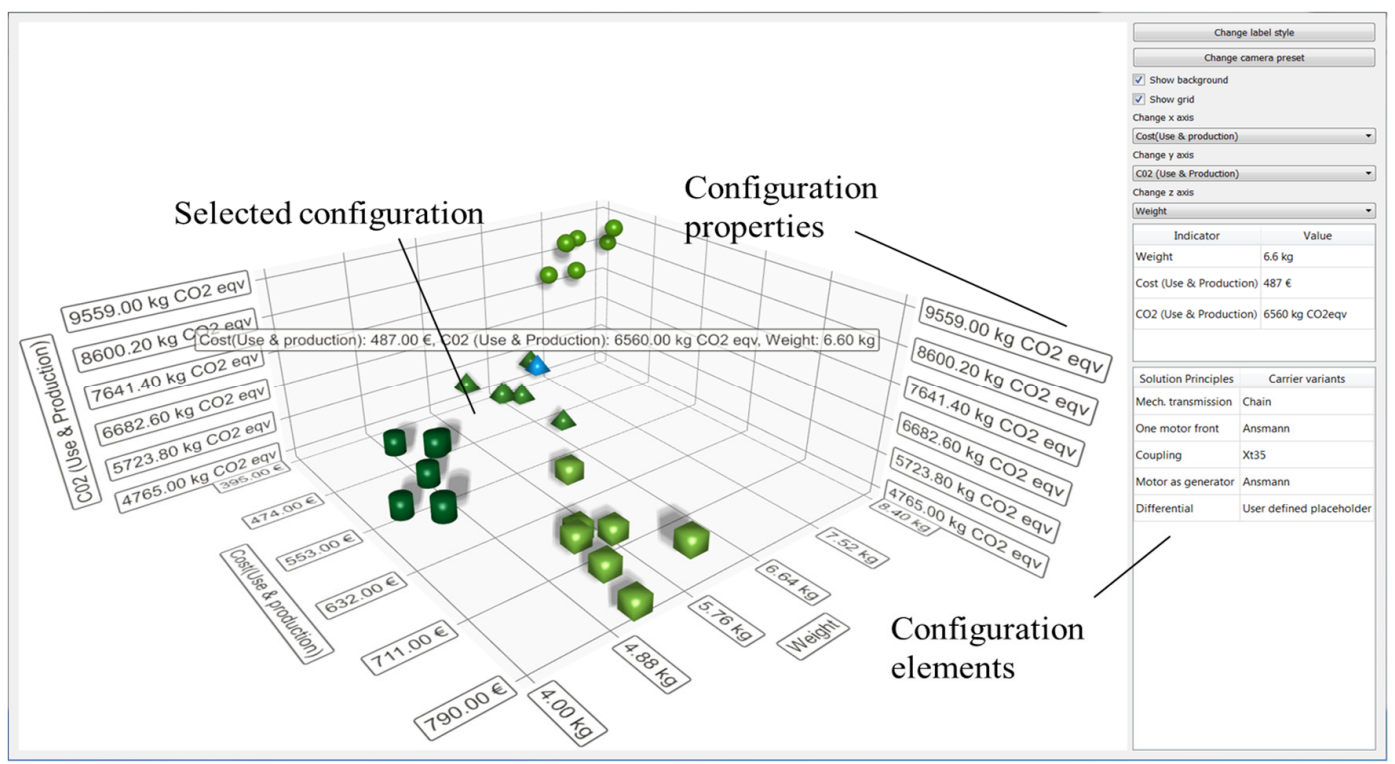

Figure 10. Visualization of results

\section{Discussion}

In the last chapters, a new approach for dealing with sustainability targets in the conceptual design phase was presented and demonstrated for a pedelec drive concept. For developing this approach some implicit assumptions were made. In the following paragraphs each assumption is presented and reflected in the context of real situation in industry.

\section{Awareness on relevant sustainability factors}

As a necessary condition for applying the proposed decision support tool, awareness on product-specific most relevant sustainability factors is required in respective companies. As the tool is able to consider any quantifiable measure, it needs to be ensured that the most relevant are selected. Larger companies already consider various KPI in their design process, which are monitored by different departments, e.g. for cost, quality, environmental or safety analysis. Nevertheless, in an empirical study which was performed to assess current industry situation regarding consideration of sustainability targets (Buchert and Stark, 2018), it was shown that most of the interviewed companies have difficulties to define relevant criteria for the broader context of sustainability. To assist companies with this task the proposed EDSS will also provide a function to give an overview of causal dependencies between overarching sustainability indicators, such as Global Warming Potential, to generic and product-specific design parameters and properties (e.g. percentage of utilized recycled materials or energy efficiency). This interactive map of indicators will help designers and design managers to derive a product-specific set of sustainability KPI.

\section{Availability of carry-over parts}

The proposed configuration approach is based on a design-related repository of existing components and assemblies. Hence, it can only be applied in a useful sense, if the amount of components made from scratch is not too high. Nevertheless, Albers et al. (2015) discovered in an empirical study involving a sample size of 159 questioned subjects (design engineers) that the majority of questioned persons use a balanced mix of carry over parts and new developed components for a new product generation. Furthermore, current and future trends, such as "modular product design" or "continuous development" suggest that future design engineering work is characterized by construction kits and more frequent development cycles implying a transition from discrete "product generations" to continuous "updates" of products. Hence, it can be argued that the share of carry-over parts will increase or at least will remain constant in the future. 


\section{Availability of information on sustainability factors}

The most significant challenge for implementing the EDSS configuration tool in a company is a proper allocation of information necessary for good results. To collect and manage all relevant information requires much effort. Hence, as described in Chapter 2, additional experts and new company roles, such as knowledge managers need to be included to build up a comprehensive database of required sustainability-relevant information. Another challenge in this context is availability of information on environmental product effects. While currently only large companies (e.g. Volkswagen) have dedicated departments for sustainability analysis, smaller companies only manage information required for legislative affirmation (e.g. hazardous substances in the context of RoHS/REACH). One effort to harmonize availability of environmental data is "Environmental Product Declaration (EPD)". EPDs are reports based on standardized quantitative environmental lifecycle-based analysis of a product, assembly or component. They are currently used on mandatory basis for communicating environmental impacts. However, in some examples EPD already are utilized for proving achievement of legislation (e.g. in France for agricultural products). Furthermore, the European Commission works on a directive for a Product Environmental Footprint (PEF) as binding legislation for environmental effects in a whole life cycle perspective. If PEF becomes a requirement for product commercialization the amount of available information will rise significantly.

\section{Limitations}

The developed configuration tool is currently realized as a prototype. For a fully applicable tool which can be utilized in industry interfaces to engineering tools need to be established. However, as Figure 5 suggests, there are various possibilities for defining interfaces. While some of these interfaces could already be established in previous work (e.g. PDM/PLM to LCA software) a real IT infrastructure implemented in a design department would be necessary to identify which information can be extracted from which system to improve collection of necessary data. It was therefore decided to concentrate on the methodological procedure and applicability of the tool for the user. A proof of concept for the overall procedure was given by the presented example of a pedelec drive concept. However, to evaluate real value for system engineers, comprehensive studies with industrial practitioners would be necessary.

Another limitation perceived in the course of this study is the consideration of social sustainability. As the tool focuses on quantitative design performance indicators there are only limited possibilities to include social factors which are qualitative in many cases (e.g. safety). Nevertheless, it might be possible to decompose social targets to quantifiable indicators. For example a low bicycle weight can contribute to customer value and in particular suit requirements for mobility of elderly people. Hence, weight can be seen as a suitable indicator suiting to the approach followed by the proposed approach.

\section{Conclusion}

The proposed approach can be seen as a valuable contribution for widening analytical capabilities of system engineers in the conceptual design phase in addition to current predominant tools for system representation (e.g. the Microsoft Office suite). If the challenges elaborated in the last chapter can be overcome, the tool will enable engineers for a more holistic view including "traditional" design performance criteria and further criteria focussing on environmental, economic and to a limited extent also social criteria. By applying the tool in conceptual design the tool can lead to pivotal improvements for developing new products.

\section{References}

Albers, A., Bursac, N. and Wintergerst, E. (2015), "Produktgenerationsentwicklung-Bedeutung und Herausforderungen aus einer entwicklungsmethodischen Perspektive", Proceeding of the 3rd Stuttgarter symposium for production development, Stuttgart, Germany, June 18-19, 2015, Fraunhofer IAO, Stuttgart.

Arnold, C.R.B., Stone, R.B. and McAdams, D.A. (2008), "MEMIC: an interactive morphological matrix tool for automated concept generation", Proceedings of the 2008 IEE Annual Conference and Expo / Industrial Engineering Research Conference (IERC '08), Vancouver, Canada, May 17-21, 2008, IISE, pp. 1196-1201. 
Baumann, H., Boons, F. and Bragd, A. (2002), "Mapping the Green Product Development Field: Engineering, Policy and Business Perspectives", Journal of Cleaner Production, Vol. 10 No. 5, pp. 409-25. https://doi.org/10.1016/S0959-6526(02)00015-X

Bohm, M.R., Haapala, K.R., Poppa, K., Stone, R.B. and Tumer, I.Y. (2010), "Integrating life cycle assessment into the conceptual phase of design using a design repository", Journal of Mechanical Design, Vol. 132 No. 9, pp. 91005. https://doi.org/10.1115/1.4002152

Brezet, H., van Hemel, C., Böttcher, H. and Clarke, R. (1997), Ecodesign: a promising approach to sustainable production and consumption, United Nations Environment Programme, Industry and Environment (UNEP IE), Rathenau Instituut and Delft University of Technology, UNEP, Paris.

Buchert, T. and Stark, R. (2018), "Integration of sustainability targets into the product creation process of german manufacturing companies", Proceedings of the 10th International Symposium on Environmentally Conscious Design and Inverse Manufacturing (EcoDesign 2017), Tainan, Taiwan, November 29-December 1, 2017.

Buchert, T., Halstenberg, F.A., Bonvoisin, J., Lindow, K. and Stark, R. (2017), "Target-driven selection and scheduling of methods for sustainable product development", Journal of Cleaner Production, Vol. 161, pp. 403-421. https://doi.org/10.1016/j.jclepro.2017.05.067

Crul, M.R.M. and Diehl, J.C. (2006), Design for sustainability: A practical approach for developing economie, United Nation Environmental Programme (UNEP), TU Delft, Paris.

Devanathan, S., Ramanujan, D., Bernstein, W.Z., Zhao, F. and Ramani, K. (2010), "Integration of sustainability into early design through the function impact matrix", Journal of Mechanical Design, Vol. 132 No. 8, pp. 081004. https://doi.org/10.1115/1.4001890

Erb, K.-H., Haberl, H., DeFries, R., Ellis, E.C., Krausmann, F. and Verburg, P.H. (2012), "Pushing the Planetary Boundaries", Science, Vol. 338 No. 6113, pp. 1419-1420. https://doi.org/10.1126/science.338.6113.1419-d

European Environment Agency (2014), Emissions of primary PM2.5 and PM10 particulate matter. [online] European Environment Agency (EEA). Available at: http://www.eea.europa.eu/data-andmaps/indicators/emissions-of-primary-particles-and-5/assessment-3 (accessed 21.11.2016).

IPCC (2014), "Summary for Policymakers", In: Edenhofer, O., Pichs-Madruga, R., Sokona, Y., Minx, J.C., Farahani, E. et al. (Eds.), Climate Change 2014: Mitigation of Climate Change Contribution of Working Group III to the Fifth Assessment Report of the Intergovernmental Panel on Climate Change, Cambridge University Press, Cambridge, New York, pp. 1-30.

Meadows, D.H., Meadows, D.L., Randers, J. and Behrens, W.W. (1972), The Limits to Growth, Potomac Associates, Washington, DC.

Oberender, C. and Birkhofer, H. (2004), "The Eco-Value Analysis-An Approach to assigning environmental impacts and costs to customers' demands", Proceedings of DESIGN 2004 / the 8th International Design Conference, Dubrovnik, Croatia, May 18-21, 2004, The Design Society, Glasgow, pp. 1553-1558.

Pahl, G., Beitz, W., Feldhusen, J. and Grote, K.-H. (2007), Pahl/Beitz Konstruktionslehre: Grundlagen erfolgreicher Produktentwicklung. Methoden und Anwendung, 7th ed., Springer, Berlin, Heidelberg. https://doi.org/10.1007/b137606

Poudelet, V., Chayer, J.-A., Margni, M., Pellerin, R. and Samson, R. (2012), “A Process-Based Approach to Operationalize Life Cycle Assessment Through the Development of an Eco-Design Decision-Support System", Journal of Cleaner Production, Vol. 33, pp. 192-201. https://doi.org/10.1016/j.jclepro.2012.04.005

Romli, A., Prickett, P., Setchi, R. and Soe, S. (2015), "Integrated eco-design decision-making for sustainable product development", International Journal of Production Research, Vol. 53 No. 2, pp. 549-571. https://doi.org/10.1080/00207543.2014.958593

Shuaib, M., Seevers, D., Zhang, X., Badurdeen, F., Rouch, K.E. and Jawahir, I.S. (2014), "Product Sustainability Index (ProdSI)", Journal of Industrial Ecology, Vol. 18 No. 4, pp. 491-507. https://doi.org/10.1111/jiec.12179

Stark, R., Buchert, T., Neugebauer, S., Bonvoisin, J. and Finkbeiner, M. (2017), "Benefits and obstacles of sustainable product development methods: a case study in the field of urban mobility", Design Science, Vol. 3, pp. e17. https://doi.org/10.1017/dsj.2017.20

United Nations General Assembly (2015), Transforming our world: the 2030 Agenda for Sustainable Development, United Nations, New York.

Verein Deutscher Ingenieure (2017), VDI 5610 Blatt 2 Wissensmanagement im Engineering - Wissensbasierte Konstruktion (KBE), Beuth Verlag.

Tom Buchert, Research Assistant

Technische Universität Berlin, Industrial Information Technology

Gryphiusstraße 21, 10245 Berlin, Germany

Email: Tom.buchert@tu-berlin.de 